\title{
Analyzing The Relation Between Communication And Empathy Skills Of Undergraduate Freshman Students In Health And Social Fields
}

\author{
Hale DERE ÇİFTÇİ ${ }^{1}$, Nurcan KOÇAK², Gökhan DUMAN ${ }^{3}$
}

\begin{abstract}
Summary
Communication is defined as producing knowledge, connection and giving meaning. Empathy is generally explained as putting oneself in another's place, understanding one's feelings and thoughts. While having good communication and empathy skills are necessary for all human beings, they are also very important especially for workers in health and social fields. These skills are the key factors for them to be happy in their work environment.

The purpose of this study was to analyze the relation between communication and empathy skills of undergraduate freshman students in health and social field registered to Turgut Ozal University. Students completed Communication Skills Evaluation Scale (CSES) and Empathy Skills Scale-B (ESS) for this purpose. Following questions were answered.

1. Is there a difference in university freshman students' communication skills in terms of gender?

2. Is there a difference in university freshman students' communication skills in terms of school type?

3. Is there a difference in university freshman students' empathy skills in terms of gender?

4. Is there a difference in university freshman students' empathy skills in terms of school type?

5. Is there a relation between university freshman students' communication and empathy skills?

To answer these questions, Personal Information Form was completed by the students. After that Communication Skills Evaluation Scale (CSES) developed by Korkut (1996) and Empathy Skills Scale-B (ESS) developed by Dokmen (1988) were used. Research group was consisted from the Faculties of Medical, Law, Economics and Administrative Sciences, Engineering and Colleges of Health Services, Nursing, and Physical Therapy and Rehabilitation. Relational screening modal was used for the research purposes. 361 female and 130 male students were voluntarily involved into study. Total of 491 scales were taking into account for analyzing. 16, $3 \%$ of the students were registered in Nursing College, 9, $4 \%$ were in Physical Therapy and Rehabilitation College, 7, 9 \% were in Medical Faculty, 13, 7 \% were in Economics and Administrative Sciences, 18, 1 \% were in Law School and 6, 5 \% were in Engineering Faculty.

Independent Groups $\mathrm{T}$ test was used to determine students' communication and empathy skills in terms of gender. One Way Anova test was used to analyze students' communication and empathy skills in terms of school type. Pearson Correlation Analysis was used to determine the correlation between students' communication and empathy skills. Findings have indicated that;
\end{abstract}

1. There is a significant difference in students' communication skills in terms of gender. It has been found that female students have better communication skills.

2. There is a significant difference in students' communication skills in terms of school type. Among schools, College of Health Services students had the higher

\footnotetext{
1 Assist. Prof., Turgut Özal University, College of Health Services, $\underline{\text { hdciftci@turgutozal.edu.tr }}$

2 Assist. Prof., Turgut Özal University, College of Health Services, nkocak@turgutozal.edu.tr

3 Assoc. Prof., Gazi University, Faculty of Education, gduman@gazi.edu.tr
} 
scores in communication skills. The lowest scores were found in Medical Faculty students. There have been significant differences found among other schools as well.

3. There isn't significant difference in students' empathy skills in terms of gender.

4. There is a significant difference in students' empathy skills in terms of school type. While Medical Faculty students had the higher scores in empathy skills, Law Faculty students had the lowest scores. There were significant differences among other schools as well.

5. It hasn't been found any correlation between students' skills of communication and empathy. 